\title{
Epidemiology of pterygium in Victoria, Australia
}

\author{
Catherine A McCarty, Cara L Fu, Hugh R Taylor
}

\begin{abstract}
Aim-To describe the prevalence of and risk factors for pterygium in a population based sample of residents of the Australian state of Victoria who were aged 40 years and older.

Methods-The strata comprised nine randomly selected clusters from the Melbourne statistical division, 14 nursing homes randomly selected from the nursing homes within a 5 kilometre radius of the nine Melbourne clusters, and four randomly selected clusters from rural Victoria. Pterygium was measured in millimetres from the tip to the middle of the base. During an interview, people were queried about previous ocular surgery, including surgical removal of pterygium, and their lifetime exposure to sunlight. Results -5147 people participated. They ranged in age from 40 to 101 years and 2850 (55.4\%) were female. Only one person in the Melbourne cohort reported previous pterygium surgery, and seven rural residents reported previous surgery; this information was unavailable for the nursing home residents. Pterygium was present upon clinical examination in 39 $(1.2 \%)$ of the 3229 Melbourne residents who had the clinical examination, six $(1.7 \%)$ of the nursing home residents, and $96(6.7 \%)$ of the rural residents. The overall weighted population rate in the population was $2.83 \%(95 \%$ CL $2.35,3.31)$. The independent risk factors for pterygium were found to be age (OR=1.23, 95\% $C L=1.06,1.44)$, male sex $(O R=2.02,95 \%$ $C L=1.35,3.03)$, rural residence $(O R=5.28$, 95\% $C L=3.56,7.84)$, and lifetime ocular sun exposure $(O R=1.63,95 \% \quad C L=1.18$, 2.25). The attributable risk of sunlight and pterygium was $43.6 \%(95 \% \mathrm{CL}=42.7,44.6)$. The result was the same when ocular UV-B exposure was substituted in the model for broad band sun exposure.

Conclusion-Pterygium is a significant public health problem in rural areas, primarily as a result of ocular sun exposure. (Br f Ophthalmol 2000;84:289-292)
\end{abstract}

Described as an "ophthalmic enigma", ${ }^{1}$ pterygium is of great concern to both surgeons and patients as it has been shown to recur in up to $97 \%$ of patients within 1 year after surgical removal. ${ }^{2}$ Although there is a large body of literature regarding the treatment of pterygium, there is a relative paucity of current information about the prevalence and risk factors for pterygium in the population ${ }^{3-5}$ other than targeted studies about UV-B and risk of pterygium. ${ }^{6-13}$ Only one study assessed total radiation as opposed to only the UV-B component. $^{9}$

The purpose of this study was to describe the epidemiology of pterygium in a representative sample of residents of the Australian state of Victoria who were aged 40 years and older.

\section{Methods}

The Visual Impairment Project (VIP) is a population based study of age related eye disease in a random sample of Victorians aged 40 years and older. ${ }^{14}$ The participants were recruited through a cluster, stratified sampling design. The strata comprised nine randomly selected clusters from the Melbourne statistical division, 14 nursing homes randomly selected from the nursing homes within a 5 kilometre radius of the nine Melbourne clusters, and four randomly selected clusters from rural Victoria. Eligible residents, all permanent residents aged 40 years and older, were recruited through a household census. At the doorstep, information was gathered about age, sex, ethnicity, education, and presence of eye disease; and people were invited to attend the test site for a complete examination. The protocol was approved by the human research ethics committee of the Royal Victorian Eye and Ear Hospital.

At locally established test sites, the standardised examination comprised the following: presenting and best corrected distance visual acuity, reading vision, visual fields, intraocular pressure, dilatation, personal interview, clinical eye examination, and photography of the lens and fundus. Pterygium was measured in millimetres from the tip to the middle of the base of the triangular band of fibrovascular tissue. Encroachment on the cornea was required for the definition of pterygium, but optical zone involvement was not. Pingueculae, fibrovascular tissue with no corneal involvement, were recorded separately. During the interview, people were queried about previous ocular surgery, including surgical removal of pterygium.

Detailed information about lifetime sun exposure was gathered. ${ }^{15}$ For each period of adult life greater than 6 months, people were asked to state where they lived and how many hours they spent outside between the hours of 9 am and $5 \mathrm{pm}$ during the weekdays and at the weekend, and for what proportion of the time outdoors they wore a hat, sunglasses, or prescription lenses. Using data about ambient UV-B levels and information about the proportion of ambient UV-B that reaches the eye under various conditions, the individual amount of ocular UV-B was calculated. The model was modified to estimate broad band sun exposure by removing the protective 
Table 1 Age and sex distribution of the participants by stratum

\begin{tabular}{|c|c|c|c|c|c|c|}
\hline Age group & $\begin{array}{l}\text { Melbourne } \\
\text { residential male }\end{array}$ & $\begin{array}{l}\text { Melbourne } \\
\text { residential female }\end{array}$ & $\begin{array}{l}\text { Melbourne nursing } \\
\text { home male }\end{array}$ & $\begin{array}{l}\text { Melbourne nursing } \\
\text { home female }\end{array}$ & Rural male & Rural female \\
\hline $40-49$ & 357 & 466 & 1 & 2 & 200 & 237 \\
\hline $50-59$ & 446 & 532 & 2 & 4 & 180 & 177 \\
\hline $60-69$ & 427 & 436 & 15 & 9 & 150 & 174 \\
\hline $70-79$ & 222 & 223 & 28 & 68 & 132 & 140 \\
\hline $80-89$ & 56 & 89 & 30 & 155 & 32 & 41 \\
\hline $90+$ & 3 & 14 & 9 & 80 & 7 & 3 \\
\hline Total & 1511 & 1760 & 85 & 318 & 701 & 772 \\
\hline
\end{tabular}

effects of hat ${ }^{16}$ and prescription lens ${ }^{17}$ use from the calculation. The Smith serially additive dose model was constructed to assess the difference in mean annual ocular UV-B and sunlight exposure between pterygium cases and controls for each year of life. ${ }^{18}$ This method allows for the assessment of critical time periods of exposure.

SAS (Cary, NC, USA) was used for the statistical analyses and a $p$ value $<0.05$ was considered to be statistically significant. Univariate relations were evaluated with the use of a $\chi^{2}$ or unpaired $t$ test. The independent effect of risk factors was evaluated with the use of logistic regression models with backwards stepwise variable selection. The log of the lifetime ocular UV-B and sunlight exposure was calculated to normalise the data and allow for parametric analyses. Age standardised rates were calculated with the total Melbourne residential sample population (Table 1) as the age standard and the $95 \%$ confidence limits (CL) were calculated by the method of Breslow and Day. ${ }^{19}$ The strata specific pterygium rates were weighted using the 1996 Australian Bureau of Statistics census data ${ }^{20}$ to derive an estimate of pterygium in the entire Victorian population. The attributable risk - that is, the percentage of pterygium in the total population as a result of a given risk factor, and 95\% CL were calculated by the method of Kahn and Sempos. ${ }^{21}$

\section{Results}

PARTICIPANT CHARACTERISTICS

The number of people seen and participation rate by stratum were 3271 (83\%) Melbourne, 403 (92\%) nursing home, and 1473 (90\%) rural. Non-participants were significantly more likely to speak a language other than English in their own homes $(78 \%$ versus $85 \%)$, but did not differ significantly in other way. ${ }^{22}$

The number (\%) of males in each group were 1511 (46.2) Melbourne, 85 (21.1) nursing home, and 701 (47.6) rural (Table 1). The mean age of the participants in each stratum was 58.7 (SD 11.4), 82.2 (9.2), and 59.0 (12.5), respectively.
PREVALENCE OF PTERYGIUM

Only one person in the Melbourne cohort reported previous pterygium surgery, and seven rural residents reported previous surgery, but this information was unavailable for the nursing home residents. Pterygium was present upon clinical examination in $39(1.2 \%)$ of the 3229 Melbourne residents that had the clinical examination, six $(1.7 \%)$ of the nursing home residents, and $96(6.7 \%)$ of the rural residents. The distribution of pterygium size was: $61(43 \%) 1 \mathrm{~mm}, 57(40 \%) 2 \mathrm{~mm}, 19$ (13\%) $3 \mathrm{~mm}$, two (1\%) $4 \mathrm{~mm}$, and three $(2 \%)$ $5 \mathrm{~mm}$. The age standardised rates of pterygium reveal higher rates in men and rural residents (Table 2). The overall rate of pterygium in the population was $2.83 \%$ (95\% CL 2.35, 3.31).

UNIVARIATE RISK FACTORS FOR PTERYGIUM

The nursing home residents were not included in the risk factor analyses as risk factor data were not systematically available for all nursing home residents. The following factors were investigated to determine if they were associated with pterygium: cluster, age, sex, rural residence, born in Australia, lifetime ocular UV-B exposure, lifetime ocular sunlight exposure, smoking history, use of vitamin E supplements, use of vitamin C supplements, cortical opacity, nuclear opacity, posterior subcapsular cataract opacity, iris colour, language spoken at home, occupation, and industry. The significant univariate factors are summarised in Table 3.

Pterygium prevalence also varied significantly by current broad industry of employment with higher rates in farmers, miners, gas and electric workers, and recreational workers $\left(\chi^{2}=90.7, \mathrm{p}=0.001\right)$, but did not vary significantly by specific occupation within a given industry $(p>0.05)$. Occupation and industry coding was done according to the Australian Bureau of Statistics. ${ }^{20}$

The pterygium risk associated with rural residence was examined more closely through the confirmation of the pterygium assessment in the study participants to rule out misclassification bias. One examiner assessed all of the

Table 2 Prevalence (\%) of pterygium by age, sex, and stratum

\begin{tabular}{|c|c|c|c|c|c|c|c|}
\hline Age group & $\begin{array}{l}\text { Melbourne males } \\
(n=1505)\end{array}$ & $\begin{array}{l}\text { Melbourne females } \\
(n=1734)\end{array}$ & $\begin{array}{l}\text { Nursing home } \\
\text { males }(n=69)\end{array}$ & $\begin{array}{l}\text { Nursing home } \\
\text { females }(n=290)\end{array}$ & $\begin{array}{l}\text { Rural males } \\
(n=691)\end{array}$ & $\begin{array}{l}\text { Rural females } \\
(n=765)\end{array}$ & $\begin{array}{l}\text { Weighted population } \\
\text { total }\end{array}$ \\
\hline $40-49$ & 0.57 & 0.44 & 0 & 0 & 5.05 & 2.53 & 1.39 \\
\hline $50-59$ & 2.49 & 0.76 & 0 & 0 & 8.38 & 3.98 & 2.81 \\
\hline $60-69$ & 2.36 & 0.93 & 0 & 12.5 & 11.7 & 2.94 & 3.41 \\
\hline $70-79$ & 1.37 & 0.9 & 0 & 1.64 & 9.92 & 5.76 & 3.30 \\
\hline $80-89$ & 1.79 & 0 & 0 & 2.11 & 31.3 & 10.0 & 6.40 \\
\hline $90+$ & 0 & 0 & 0 & 1.35 & 33.3 & 0 & 1.90 \\
\hline $\begin{array}{l}\text { Age standardised } \\
\text { rate }(95 \% \mathrm{CL})\end{array}$ & $1.76(1.09,2.42)$ & $0.71(0.31,1.10)$ & 0 & $3.62(0,10.1)$ & $9.78(7.39,12.2)$ & $3.83(2.42,5.24)$ & $2.83(2.35,3.31)$ \\
\hline
\end{tabular}


Table 3 Significant univariate risk factors for pterygium

\begin{tabular}{lllcl}
\hline Risk factor & $\begin{array}{l}\text { Pterygium cases } \\
(n=142)\end{array}$ & $\begin{array}{l}\text { Controls } \\
(n=4902)\end{array}$ & $\begin{array}{c}\text { Test } \\
\text { statistic }\end{array}$ & $p$ Value \\
\hline Mean age (SD) & $64.3(12.6)$ & $60.3(13.0)$ & 3.720 & 0.0003 \\
Log lifetime ocular sun (SD) & $-0.08(0.80)$ & $-0.50(0.63)$ & 5.82 & 0.0001 \\
Male (\%) & 66.2 & 44.1 & 27.3 & 0.001 \\
Rural (\%) & 68.3 & 27.7 & 110.7 & 0.001 \\
Smokers (\%) & 14.7 & 17.5 & 32.8 & 0.001 \\
Percentage who take vitamin E & 3.6 & 9.0 & 5.0 & 0.03 \\
Percentage who take vitamin C & 3.6 & 11.2 & 8.20 & 0.004 \\
Percentage with cortical opacity $>4 / 16$ & 22.3 & 13.1 & 10.0 & 0.002 \\
Percentage with any PSC opacity & 12.4 & 5.7 & 10.8 & 0.001 \\
Percentage with nuclear opacity $>2$ & 25.6 & 16.0 & 9.0 & 0.003 \\
Percentage born in Australia & 83.8 & 64.6 & 21.6 & 0.001 \\
\hline
\end{tabular}

Table 4 Significant multivariate risk factors for pterygium

\begin{tabular}{lll}
\hline Risk factor & Odds ratio & $95 \% C L$ \\
\hline Age group (10 year) & 1.23 & $1.06,1.44$ \\
Male sex & 2.02 & $1.35,3.03$ \\
$\begin{array}{l}\text { Rural residence } \\
\text { Lifetime ocular sun exposure } \\
\quad(0.01 \text { log MSY) }\end{array}$ & 5.28 & $3.56,7.84$ \\
\hline
\end{tabular}

Melbourne participants, while a second examiner who was trained by the first examiner with the standardised protocol, examined all of the rural residents. With the exception of a few of the pterygium less than $1 \mathrm{~mm}$, all of the cases in the rural location could be seen on the retroillumination photos (data not presented). We therefore do not believe that there was any systematic misclassification bias that would explain the observed urban/rural difference in pterygium prevalence.

MULTIVARIATE RISK FACTORS FOR PTERYGIUM All of the significant univariate risk factors for pterygium were placed in a logistic regression model with backwards selection of variables. The independent risk factors for pterygium were found to be age, sex, rural residence, and lifetime ocular sun exposure (Table 4). The same results were found when lifetime ocular UV-B exposure was substituted in the model for the sun (data not shown). A log transformation was employed with the sun exposure variable because the data were skewed to the left. The odds ratio for this variable can be interpreted as the increased risk of pterygium for each 0.01 increase in Melbourne sun years of sunlight exposure.

Total radiation (visible light) and pterygium

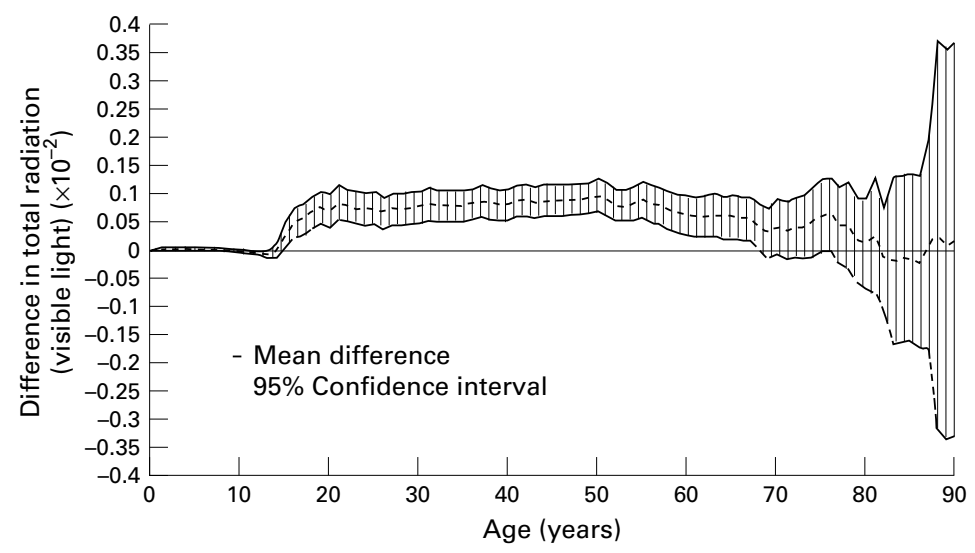

Figure 1 Mean difference in ocular sun exposure between pterygium cases and controls at each year of life.
The relation of UV-B and sunlight with pterygium was examined in more detail. With the use of the Smith serially additive dose model, ${ }^{18}$ we found that there was not a critical time for exposure, but that mean ocular sun exposure was higher in pterygium cases than controls for all adult years between the ages of 15 and 68 (Fig 1). The data are similar for the relation of UV-B and pterygium (data not shown). Lifetime ocular UV-B and lifetime ocular broadband sun exposure were highly correlated $(r=0.82, \mathrm{p}=0.0001)$.

Ocular sunlight exposure was categorised into the upper and lower halves of the distribution to calculate population attributable risk. ${ }^{21}$ The attributable risk of sun exposure and pterygium was $43.6 \%(42.7,44.6)$. Stratification of the effect of sun exposure by location (urban versus rural) revealed that the relation is the same after controlling for age and sex, although not significant in the urban areas because of the lower lifetime ocular sun exposure.

\section{Discussion}

To our knowledge, this is the first population based study to compare the rates of pterygium between urban and rural areas. We found that the rates of pterygium in country residents are more than five times as high as urban residents, and that in both groups, UV-B/sunlight is the primary risk factor for pterygium.

There have been only two population based studies of pterygium prevalence in Australia in the past two decades. ${ }^{358}$ Data from the national trachoma and eye health programme conducted in the mid 1970s in a non-randomly selected group of white people and nearly half of the Aboriginal population revealed pterygium rates of $9.9 \%$ in non-Aboriginal males and $4.4 \%$ in non-Aboriginal females aged $40-59$. The rates were $12.0 \%$ and $6.1 \%$ in males and females aged $60+{ }^{8}$ These pterygium rates are similar to the rates from the Blue Mountains eye study, ${ }^{5}$ where rates of $11 \%$ in men and $4.5 \%$ in women were reported. The pterygium rates in the rural component of the Visual Impairment Project of $10 \%$ in men and $4 \%$ in women are remarkably similar to the rates from the other studies, both of which were sampled from rural areas, while the urban Visual Impairment Project rates were considerably lower.

We know of only one other attempt to comprehensively assess risk factors for pterygium and present them in one manuscript. ${ }^{4}$ In this case-control study conducted in a Brisbane hospital, ultraviolet light exposure (measured as latitude of residence, living environment, time spent outdoors, and use of a hat) in the early years of life was found to be associated with the development of pterygium. In contrast, we found that sun/UV-B exposure throughout almost all of the adult years was an important risk factor for the prevalence of pterygium. The Smith serially additive dose model does not reveal significant differences in childhood mean annual ocular UV-B/sunlight exposure, perhaps because the VIP questionnaire is relatively insensitive to exposures 
during childhood. ${ }^{15}$ However, after controlling for sun/UV-B exposure in a multivariate logistic regression model, we found that residence during the first 5 years of life was not related to the development of pterygium (data not presented). These findings stress the importance of precise exposure measurement that includes measures of personal behaviour. The questionnaire employed in our study incorporates all available information about ambient UV-B, personal sunlight exposure and sun protection behaviours, and ocular exposure ratios to produce a comprehensive measure of ocular sun/UV-B exposure, rather than proxy measures such as location residence. ${ }^{15}$

We found that a large proportion of the pterygium prevalence in Victoria (44\%) was due to UV-B/sunlight exposure, which supports the findings of several other studies. . $^{3-5} 89$ We were not able to replicate the finding of the Blue Mountains eye study that pigmentation was associated with pterygium, ${ }^{5}$ again probably because we have a more precise measure of sun/UV-B exposure which perhaps explains the discrepancy. The other remaining independent risk factors in our multivariate logistic regression models were age group, male sex, and rural residence. In fact, all three of these factors may be proxy measures for higher levels of sun/UV-B exposure. Previously, we have shown that the older age cohorts have higher levels of ocular UV-B exposure because of lower levels of sunglass use..$^{22-24}$

In conclusion, pterygium is a significant public health problem in rural areas, primarily due to ocular sun exposure. People should be strongly encouraged to wear a wide brimmed hat and sunglasses whenever they are outside as personal behaviours can have an 18-fold impact on the ocular dose of UV-B. The Visual Impairment Project was supported in part by grants from the National Health and Medical Research Council, the mology Foundation, the estate of the late Dorothy Edols, the mology Foundation, the estate of the late Dorothy Edols, the Jack Brockhoff Foundation and the Ophthalmic Research Institute of Australia. Dr McCarty is a recipient of the Wagstaf Research Fellowship in Ophthalmology from the Roya Victorian Eye and Ear Hospital. The rural field work was supported by the Lions and Apex Clubs of Bright.
1 Coster D. Pterygium - an ophthalmic enigma. Brf Ophthalmol 1995; 79:304-5.

2 Hirst LW, Sebban A, Chant D. Pterygium recurrence time. Ophthalmology 1994;101:755-8.

3 Taylor HR. Aetiology of climatic droplet keratopathy and pterygium. Br f Ophthalmol 1980;64:154-63.

4 Mackenzie FD, Hirst LW, Battistutta D, et al. Risk analysis in the development of pterygia. Ophthalmology 1992;99: 056-61.

5 Panchapakesan J, Hourihan F, Mitchell P. Prevalence of pterygium and pinguecula: the Blue Mountains Eye Study. Aust NZ F Ophthalmol 1998;26:S2-5.

6 Detels R, Dhir SP. Pterygium: a geographical study. Arch Ophthalmol 1967;78:485-91.

7 Dhir SP, Detels R, Alexander ER. The role of environmental factors in cataract, pterygium and trachoma. $\mathrm{Am} \mathcal{F} \mathrm{Oph}-$ thalmol 1967;64:128-35.

8 Moran DJ, Hollows FC. Pterygium and ultraviolet radiation: a positive correlation. Br $\mathcal{F}$ Ophthalmol 1984;68: 343-6.

9 Taylor HR, West SK, Rosenthal FS, et al. Corneal changes associated with chronic UV irradiation. Arch Ophthalmol 1989;107:1481-4.

10 Coroneo MT. Albedo concentration in the anterior eye: a phenomenon that locates some solar diseases. Ophthalmic Surg 1990;21:60-6.

11 Coroneo MT, Müller-Stolzenburg NW. Peripheral light focusing by the anterior eye and the ophthalmohelioses. Ophthalmic Surg 1991;22:705-11.

2 Coroneo MT. Pterygium as an early indicator of ultraviolet insolation: a hypothesis. Br F Ophthalmol 1993;77:734-9.

13 Karukonda SRK, Thompson HW, Beuerman RW, et al. Cell cycle kinetics in pterygium at three latitudes. Br f Ophthalmol 1995;79:313-17.

14 Livingston PM, Carson CA, Stanislavsky YL, et al. Methods for a population-based study of eye disease: the Melbourne visual impairment project. Ophthalmic Epidemiol 1994;1: 139-48.

15 McCarty CA, Lee SE, Livingston PM, et al. Ocular exposure to UV-B in sunlight: the Melbourne visual impairment project model. WHO Bull 1996;74:353-60.

16 Duncan DD, Muñoz B, Bandeen-Roche K, et al. Visible and ultraviolet-B ocular-ambient exposure ratios for a general population. Invest Ophthalmol Vis Sci 1997;38:1003-11.

17 Rosenthal FS, Bakalian AE, Lou C, et al. The effect of sunglasses on ocular exposure to ultraviolet radiation. Am f Publ Health 1988;78:72-4.

18 Smith AH, Waxweiler RJ, Tyroler HA. Epidemiologic investigation of occupational carcinogenesis using a serially additive expected dose model. Am f Epidemiol 1980;112: 787-97.

19 Breslow NE, Day NE. Statistical methods in cancer research. Volume II. The design and analysis of cohort studies. Lyons: International Agency for Research on Cancer, 1987.

20 Australian Bureau of Statistics. 1996 census of population and housing. Canberra: ABS, 1997.

21 Kahn HA, Sempos CT. Statistical methods in epidemiology. New York: Oxford University Press, 1989

22 Livingston PM, Lee SE, McCarty CA, et al. A comparison of participants with non-participants in a population-based epidemiologic study: the Melbourne visual impairment project. Ophthalmic Epidemiol 1997;4:73-81.

23 McCarty CA, Taylor HR. Protecting eyes from sun damage. Med F Aust 1997;166:671.

24 McCarty CA, Taylor HR. Recent developments in vision research: light damage in cataract. Invest Ophthalmol Vis Sci 1996;37:1720-3. 